\section{The importance of a patient's background in formulating a management approach}

\author{
Anil Ojha, Pawan Shrestha, \\ David A. Green \\ Kathmandu Medical College Teaching \\ Hospital, Kathmandu, Nepal
}

\begin{abstract}
Peptic ulcer disease is uncommon in childhood, with non-specific clinical features. A tendency to late diagnosis makes it more likely for a patient to present with complications. Here we discuss a child with low socio-economic status from a developing country who presented with severe anemia secondary to a bleeding duodenal ulcer. The case highlights the importance of the patient's background in the formulation of a management approach. In some cases this may be intuitive to an experienced physician. However, we demonstrate this with a simple mathematical diagnostic model using disease prevalences which are tied to our individual patient's circumstances. The model shows how the negative predictive value of a test can change according to the patient's background. We also suggest that the best treatment option will be influenced by the patient's circumstances. Our patient comes from Nepal, but the principles involved are universally applicable.
\end{abstract}

\section{Case Report}

A 12-year-old Nepali boy presented with a 2day history of black tarry stools, a similar episode 6 months previously, and 6 months of recurrent upper abdominal pain, worse after meals, increasing pallor, palpitations and dyspnea on exertion. There was no drug use, nor contact with tuberculosis. Positive findings were pallor, tachycardia, tachypnea, epigastric tenderness, soft systolic murmur, hemoglobin of $2.3 \mathrm{gm} / \mathrm{dL}$, microcytic, hypochromic erythrocytes, and stool positive for blood. Relevant negative findings were absence of rash, jaundice, lymphadenopathy, organomegaly, malnutrition, and hookworm in stool. Platelet and white cell counts were normal.

Endoscopy (after transfusion) showed a large, solitary ulcer in the first part of the duodenum, with exudates over the base, surrounding edema and slight oozing of blood. Subsequent histopathology showed chronic inflammatory changes, with no histological evidence of metaplasia, atrophy or
Helicobacter pylori (HP) infection.

He remained well on triple therapy [2 weeks of proton pump inhibitor (PPI), amoxicillin and clarithromycin ], followed by oral iron and an additional three weeks of PPI. He was counseled not to smoke or use non steroidal antiinflammatory drugs (NSAID). At 4 weeks follow up he returned to his normal activities. Examination was normal, he had no occult blood in his stool and his hemoglobin level increased satisfactorily. At 6 months follow up, he remained well, examination was normal and his hemoglobin was $13.4 \mathrm{gm} / \mathrm{dL}$.

\section{Discussion}

We elected to give short term triple therapy despite no evidence of HP infection, and presented this to highlight the importance of a patient's background in formulating a management approach.

The prevalence of HP is lower in bleeding than non-bleeding peptic ulcers, but similar if the comparison is limited to patients not taking NSAIDs. ${ }^{1}$ Furthermore, detection of HP can be elusive in acutely bleeding cases. Delayed testing ( $\geq 4$ weeks after bleeding) and testing in younger patients, give a prevalence of $\mathrm{HP}$ approaching that seen in non-bleeding ulcers. ${ }^{2}$

Early reviews showed HP infection rates of 80 to $95 \%$ in duodenal ulcer (DU) patients ${ }^{3}$ in developed countries. Rates are now dropping there, but remain high in developing countries. If we assume a prevalence of $90 \%$ in patients like ours, then in Table 1 cell $\mathrm{e}=90$ and cell $f=10$. In the presence of a recently bleeding DU, the sensitivity and specificity of histology testing for HP is 70 and $90 \%$, respectively. ${ }^{4}$ Thus: cell $\mathrm{a}=0.7 \times \mathrm{x} 90=63$; cell $\mathrm{c}=27$; cell $d=0.9 \times 10=9$; cell $b=1$. The negative predictive value (NPV) of the histology for HP in our patient is $9 / 36=0.25$. Thus, even in the face of a negative test, a patient like ours is likely to have an HP infection.

This contrasts with the same scenario in a developed country. In a study of 144 nonNSAID using DU patients in New York, HP prevalence was $61 \% .^{5}$ If we use this prevalence in the model $(\mathrm{e}=61)$ with the same sensitivity and specificity estimates, then $\mathrm{NPV}=0.66$.

Table 1. One hundred hypothetical patients with bleeding duodenal ulcer in a developing country.

\begin{tabular}{lccc} 
& Truly HP + & Truly HP - & Total \\
Histology + for HP & $\mathrm{a}=63$ & $\mathrm{~b}=1$ & 64 \\
Histology - for HP & $\mathrm{c}=27$ & $\mathrm{~d}=9$ & 36 \\
\hline Total & $\mathrm{e}=90$ & $\mathrm{f}=10$ & 100 \\
\hline
\end{tabular}

HP, Helicobacter pylori; +, positive; -, negative.
Correspondence: David Anthony Green, Kathmandu Medical College Teaching Hospital, 184 Baburam Acharya Sadak, 44600 Kathmandu, Nepal.

Tel. +977.661.447472857 - Fax: +977.661.89516976.

E-mail: david.green@nt.gov.au

Key words: Helicobacter pylori, negative predic tive value, management approach.

Contributions: the authors contributed equally.

Conflict of interests: the authors declare no potential conflict of interests.

Received for publication: 11 February 2013.

Revision received: 3 May 2013

Accepted for publication: 4 May 2013.

This work is licensed under a Creative Commons Attribution 3.0 License (by-nc 3.0).

(C) Copyright A. Ojha et al., 2013

Licensee PAGEPress, Italy

Healthcare in Low-resource Settings 2013; 1:e20 doi:10.4081/hls.2013.e20

Thus, a patient is probably not infected.

In the Western literature the general consensus is for long-term antisecretory therapy after HP eradication in bleeding DU cases. ${ }^{6}$ However, Liu et al. found that after successful eradication with short-term PPI, ongoing therapy made no difference to ulcer recurrence or HP re-infection on long term follow up. ${ }^{7}$ In our case the local context was dominated by a high prevalence of enteral infections (favouring preservation of an effective acid gastric barrier), and concern about ongoing treatment costs: we therefore opted against long term acid suppression.

\section{Conclusions}

Most of the medical literature comes from the developed world, and colleagues in the developing world by necessity use this body of evidence to inform their clinical practice. However, patients' backgrounds are very different in these two worlds, and we offer this 
case as a reminder of the importance of a 2. Sánchez-Delgado J, Gené E, Suárez D, et patient's background in the formulation a management approach.

\section{References}

1. Gisbert JP, Gonzalez L, de Pedro A, et al. Helicobacter pylori and bleeding duodenal ulcer: prevalence of the infection and role of non-steroidal anti-inflammatory drugs. Scand J Gastroentero 2001;36:717-24. al. Has H. pylori prevalence in bleeding peptic ulcer been underestimated? A metaregression. Am J Gastroenterol 2011;106: 398-405.

3. Barody TJ, George LL, Brandl S, et al. Helicobacter pylori-negative duodenal ulcer. Am J Gastroenterol 1991;86:1154.

4. Gisbert, JP, Abraira, V. Accuracy of Helicobacter pylori diagnostic tests in patients with bleeding peptic ulcer: a systematic review and meta-analysis. Am J Gastroenterol 2006;101:848.

5. Jyotheeswaran S, Shah AN, Jin HO, et al. Prevalence of Helicobacter pylori in peptic ulcer patients in greater Rochester, NY: is empirical triple therapy justified? Am J Gastroenterol 1998;93:574-8.

6. National Institutes of Health. NIH Consensus Conference. Helicobacter pylori in peptic ulcer disease. NIH Consensus development panel on Helicobacter pylori in peptic ulcer disease. JAMA-J Am Med Assoc 1994;272:65.

7. Liu CC, Lee CL, Chan CC, et al. Maintenance treatment is not necessary after Helicobacter pylori eradication and healing of bleeding peptic ulcer: a 5-year prospective, randomized, controlled study. Arch Intern Med 2003;163:2020-4. 